\title{
Environmental Impact Analysis of Wastewater Treatment Process Based on Life Cycle Assessment
}

\author{
Chenchen Zhao ${ }^{1, a}$, Yun Zhang ${ }^{1, b}$, Kaiming Liang ${ }^{1, ~ c}$, Jinhua $\mathrm{Li}^{1, \mathrm{~d}}$ \\ ${ }^{1}$ Key Laboratory of Industrial Ecology and Environmental Engineering (MOE), School of \\ Environmental Science and Technology, Dalian University of Technology, 2 Linggong Road, Dalian \\ 116024,China \\ azhaochenchen0704@126.com, bzhangyun@dlut.edu.cn, \\ 'kennightbrother@126.com, ${ }^{\mathrm{d}}$ lijinhua@mail.dlut.edu.cn
}

Keywords: life cycle assessment (LCA), wastewater treatment plant(WWTP), water reuse, biological filter process, SBR, environmental impact.

\begin{abstract}
Method of life cycle assessment (LCA) was applied to compare the environmental impacts of biological filter process and SBR process in two wastewater treatment plants which effluent quality reach to the same standard. Nine types of environmental impacts were constructed by using Gabi 5.0 software. After considered water reuse, the results indicate that marine aquatic toxicity potential (MAETP) of two plants contribute most which value is 3.69E-13 and 2.04E-13 respectively;Ozone depletion potential (ODP) can be negligible when compared with other impacts.
\end{abstract}

\section{Introduction}

In recent years, the emission standard for wastewater treatment plant(WWTP) of national and local become more and more strict $[1,2]$, how to choose a wastewater treatment process which can make the effluent stability achieve the national and local standards is the key problem what the WWTP faced. Liaoning Province published the new standard (DB21/1627-2008) in 2008 which pointed out the effluent of WWTP which in urban central should implement the "Grade A" standard of Discharge standard of pollutants for municipal wastewater treatment plant (GB18918-2002) [3], this means the requirement for wastewater treatment is no longer discharged after treatment, but treat wastewater for recycle [4]. On the premise of qualified effluent quality, how to choose a WWTP process which causes smaller environmental impact is important for regional sustainable development.

\section{Life Cycle Assessment}

Goal and scope definition. This paper selects two wastewater treatment plants A and B in Dalian of Liaoning province which effluents quality reached the level of the "Grade A" standard. The main process of WWTP A is biological aerated filter and the process of plant B is SBR process constants water level sequencing batch reactor process. Part of effluent will be reused and the water reuse rate of plant A and B are $100 \%$ and $6.2 \%$, the water quality indicators are shown in table1.

Table 1 water quality indicators of wastewater treatment plant $\mathrm{A}$ and $\mathrm{B}(\mathrm{mg} / \mathrm{L})$

\begin{tabular}{cccccccc}
\hline & & $\mathrm{COD}(\mathrm{mg} / \mathrm{L})$ & $\mathrm{BOD}_{5}(\mathrm{mg} / \mathrm{L})$ & $\mathrm{SS}(\mathrm{mg} / \mathrm{L})$ & $\mathrm{NH}_{3}-\mathrm{N}(\mathrm{mg} / \mathrm{L})$ & $\mathrm{TN}(\mathrm{mg} / \mathrm{L})$ & $\mathrm{TP}(\mathrm{mg} / \mathrm{L})$ \\
\hline \multirow{2}{*}{ Plant A } & Inlet & 217 & 105.5 & 135 & 15.57 & 23.89 & 3.42 \\
& Oulet & 24.62 & 2.5 & 2.98 & 2.74 & 10.99 & 0.44 \\
Plant B & Inlet & 239 & 78.86 & 325 & 19.27 & 1.73 & 8.12 \\
& Oulet & 26.3 & 6.86 & 6 & 1.10 & 0.39 & 7.15 \\
\hline
\end{tabular}

For this research, in order to eliminate some possible difficulties caused by process-based LCA, the input-output based LCA methodology is used in this paper and the sub-boundary will not be drawn [5]. This paper only considers interest in the operation phase [6, 7], the inputs of the systems are electricity and chemicals; and the outputs are effluent and sludge. Sludge disposal is not 
included in the system boundary. Fig. 1 and fig. 2 show the system boundaries of plant A and plant B.

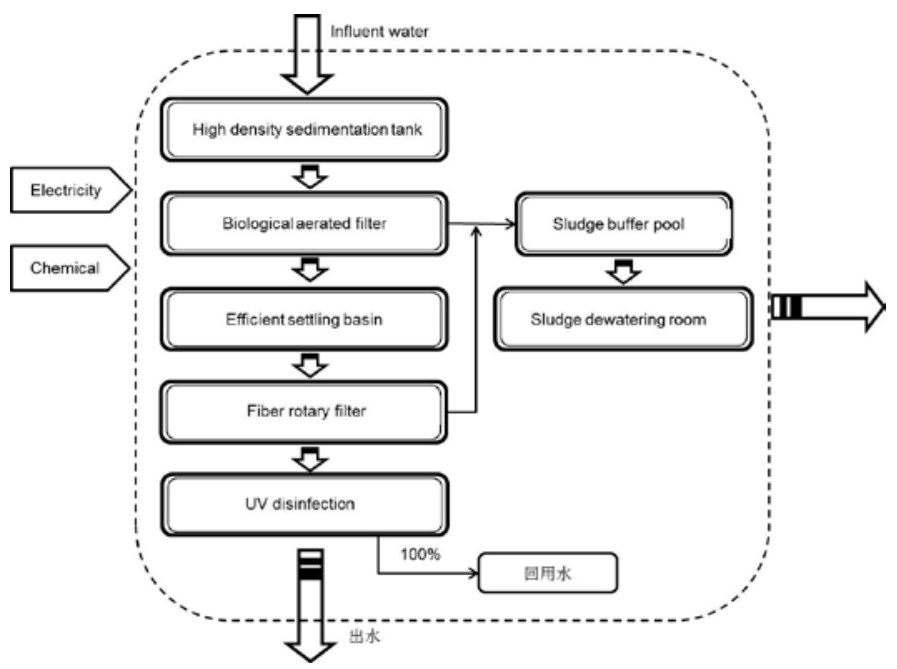

Fig.1 Life cycle assessment system boundary of wastewater treatment plant A

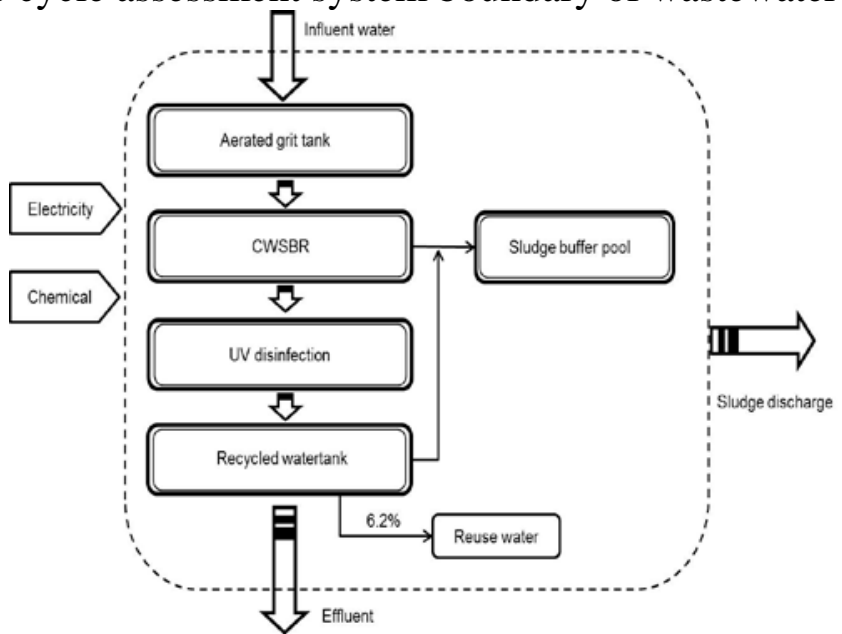

Fig.2 Life cycle assessment system boundary of wastewater treatment plant B

Inventory analysis. Following the goal and scope definition, life cycle inventory analysis is conducted according to primarily materials and energy consumption in the input items and output items. Details are presented in table 2 and table 3, and the functional unit is $1 \mathrm{~m}^{3}$ of wastewater.

Table 2 Life cycle inventory of wastewater treatment plant A

\begin{tabular}{|c|c|c|c|c|c|}
\hline Input & Unit & Number & Output & Unit & Number \\
\hline COD & $\mathrm{kg}$ & 0.217 & COD & $\mathrm{kg}$ & 0.02462 \\
\hline $\mathrm{TN}$ & $\mathrm{kg}$ & 0.02389 & $\mathrm{TN}$ & $\mathrm{kg}$ & 0.01099 \\
\hline $\mathrm{TP}$ & $\mathrm{kg}$ & 0.00342 & $\mathrm{TP}$ & $\mathrm{kg}$ & 0.00044 \\
\hline Electricity & kwh & 0.36 & Sludge & $\mathrm{kg}$ & 0.2325 \\
\hline PAM & $\mathrm{kg}$ & 0.000775 & & & \\
\hline $\mathrm{FeCl}_{3}$ & $\mathrm{~kg}$ & 0.04 & & & \\
\hline \multicolumn{6}{|c|}{ Table 3 Life cycle inventory of wastewater treatment plant B } \\
\hline Input & Unit & Number & Output & Unit & Number \\
\hline COD & $\mathrm{kg}$ & 0.239 & COD & $\mathrm{kg}$ & 0.00812 \\
\hline $\mathrm{NH}_{3}-\mathrm{N}$ & $\mathrm{kg}$ & 0.01927 & $\mathrm{NH}_{3}-\mathrm{N}$ & $\mathrm{kg}$ & 0.0011 \\
\hline TP & $\mathrm{kg}$ & 0.00173 & TP & $\mathrm{kg}$ & 0.00039 \\
\hline Electricity & kwh & 0.2050 & Sludge & $\mathrm{kg}$ & 0.318 \\
\hline $\mathrm{FeSO}_{4}$ & $\mathrm{~kg}$ & 0.0070 & & & \\
\hline
\end{tabular}


The data of water quality, chemical and electricity are provided by the WWTPs under study; the background data of the power and the chemical from the Gabi5.0 of the PE database. This paper chooses CML2001 - Nov. 2010 method to calculate the environment impacts.

Environmental Assessment and Results. Using Gabi5.0 software to build the process model of sewage treatment, CML2001-Nov. 2010 method was used to calculate the environmental effects of A and B. As the WWTP A and B are related to the effluent reuse, plant A reuses the effluent can reach to $100 \%$, this part of environment impact can't be ignored with the saving resources, so calculate the environmental impact generated by production water will be necessary, as the water reuse the avoidable environmental load. Field and purpose of reclaimed water are not considered in this paper and the reused water is counted as the saved amount of fresh water and the environmental impact of producing fresh water as an avoided load [8]. In this paper, tap water production process is using Gabi5.0 software its own tap water production process model. After considering the effects of reuse water, life cycle environmental impact assessment results of WWTP A and B can be seen in figure 3.

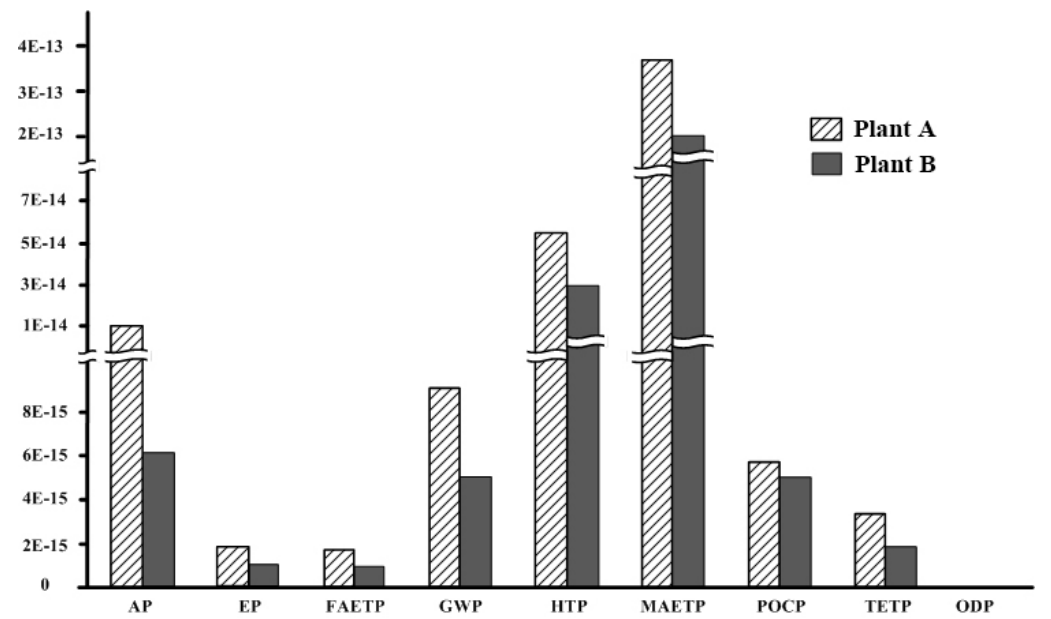

Fig.3 Life cycle assessment results of wastewater treatment plants A and B after considering water reuse

As indicated in the fig 3 it can be seen that the MAETP contributes most to the overall impacts in both plant A and B and the ozone depletion potential is found to be negligible compared with other impacts. Changes in the nine types of indicators of plant A and B are similar, but the values of plant $A$ are higher than plant $B$, this is because plant $A$ processing $1 \mathrm{~m}^{3}$ wastewater consumes more electricity and chemicals than plant $\mathrm{B}$, one hand is due to plant A treatment process is more complex than plant B; on the other hand is due to the geographical location of plant $B$, the sludge can be directly pumped from sludge storage tank into the sludge treatment plant, compared with plant A the sludge dewatering process is omitted, this indirect saving consumption. Based on the two aspects mentioned above, the values of plant $\mathrm{A}$ are higher than plant $\mathrm{B}$.

About the effluent reuse, even though the effluent reuse rate of wastewater treatment plant $B$ is only $6.2 \%$, the life cycle environmental impact results of plant B are still lower than plant A can be seen from figure 3 , it indicated that wastewater treatment process plays a major role on the environmental impact resulting. Effluent reuse can only play a supplementary role in reducing environmental impact, and process selection determines the size of the environment influence in a great extent.

\section{Conclusion}

This paper elevated life cycle environmental impact of two wastewater treatment processes and nine kinds of environmental impacts were calculated by using Gabi5.0 software to carry out the life cycle environmental impact assessment, the conclusion as follows:

(1) Environment impact of plant B is lesser than it produced by plant A, among the impact types, AP, GWP, HTP, MAETP have obvious difference; marine aquatic toxicity potential (MAETP) result 
values are maximal in both plant A and plant B, respectively $3.69 \mathrm{E}-13$ and $2.04 \mathrm{E}-13$, the result value of ozone layer depletion potential (ODP) is smallest and it can be neglected when compared with other types of environment impact.

(2) Effluent reuse rate of plant $A$ is far higher than plant $B$, but after considering water reuse its environmental impact is still higher than plant $\mathrm{B}$, it indicated that the choice of treatment technology effect the environment in a large part, while the effluent reuse play a supporting role in reducing the environmental impact.

Therefore in the premise of meeting the water quality standards, the life cycle environmental impact of treatment process should be paid more attention to the investigation and actual situation also should be examining, comprehensive consideration the process choice in order to facilitate the regional sustainable development.

\section{Acknowledgments}

This study was supported by the Major Science and Technology Program for Water Pollution Control and Treatment (2012ZX07202-001).

Corresponding author: Zhang Yun.

Email: zhangyun@dlut.edu.cn

\section{Reference}

[1] DB12/356-2008, Tianjin city Integrated wastewater discharge standard. Standardization Administration of the People's Republic of China, SAC.

[2] DB11/890-2012, Beijing Discharge standard of water pollutants for municipal wastewater treatment plant. Standardization Administration of the People's Republic of China, SAC.

[3] DB21/1627-2008, Liaoning city Integrated wastewater discharge standard. Standardization Administration of the People's Republic of China, SAC.

[4] X. C. Zheng, W. Shang, Y. L. Sun, et al. Analysis and suggestions of urban wastewater treatment process which stable reach level A standard. Water \& Wastewater Engineering. 35 (2009) 24-28.

[5] Q. H. Zhang, X. C. Wang, J. Q. Xiong, et al. Application of life cycle assessment for an evaluation of wastewater treatment and reuse project - case study of Xi'an,China. Bioresource Technology.101 (2010) 1421-1425.

[6] P. Pradip Kalbar,Subhankar Karmakar, R. Shyam Asolekar. Assessment of wastewater treatment technologies: life cycle approach.Water and Environment Journal. 27 (2013) 261-268.

[7] Montse Menesesa, C. Jorgelina Pasqualino, Francesc Castells. Environmental assessment of urban wastewater reuse:treatment alternatives and applications. Chemosphere Environmental Toxicology and Risk Assessment. 8 (2010) 266-272.

[8] C. Jorgelina Pasqualinom, MontseMeneses, Francesc Castells. Life cycle assessment of urban wastewater reclamation and reuse alternatives. Industrial Ecology. 15 (2011) 49-63. 